\title{
A LUDICIDADE NO DESENVOLVIMENTO DA CRIANÇA: UMA EXPERIÊNCIA DE INICIAÇÃO CIENTÍFICA
}

\author{
Aline ABREU, Aline ALMEIDA, Adriano ROBERTO, Berilene \\ OLIVEIRA, Ígora DACIO, Jessica MAIA, Juliana SANTOS, \\ Juliete SILVA, Mirene FERREIRA, Ruth ASSIS, Sirley \\ PEREIRA, Victória VERAS
}

\author{
Waldir Ferreira de ABREU ${ }^{2}$ \\ awaldir@ufpa.br \\ Damião Bezerra OLIVEIRA ${ }^{3}$ \\ damiao@ufpa.br
}

Resumo: $A$ atividade lúdica na educação, representada por jogos e brincadeiras, pode desenvolver o aprendizado da criança na sala de aula. O lúdico se apresenta como ferramenta de ensino para o desempenho e o desenvolvimento integral das crianças, proporcionando momentos de alegria, aprendizado e comprometimento com o aprender. $O$ artigo é resultado das atividades de iniciação científica desenvolvidas pelo Grupo de Estudos e Pesquisas em Educação, Infância e Filosofia - GEPEIF/CNPq/UFPA, vinculado ao projeto de extensão, coordenado pelos professores Waldir Ferreira de Abreu e Damião Bezerra Oliveira: O lúdico como recurso didático na formação da criança. Tem como objetivo discutir a importância do lúdico no processo de desenvolvimento da criança, sobretudo na Educação Infantil, e apresentar as atividades lúdicas desenvolvidas com as crianças das escolas dos rios Quianduba e Ajuaí, em uma oficina sobre o lúdico.

Palavras-chave: Ludicidade. Desenvolvimento. Criança.

\footnotetext{
${ }^{1}$ Alunos(as) do curso de Pedagogia do Campus Universitário de Abaetetuba - UFPA e bolsistas do Grupo de Estudos e Pesquisas em Educação, Infância e Filosofia GEPEIF/UFPA/CNPq.

${ }^{2}$ Doutor em Ciências Humanas e Educação pela PUC/RIO, Professor Adjunto II da Universidade Federal do Pará, líder do Grupo de Estudos e Pesquisas em Educação, Infância e Filosofia - GEPEIF/UFPA/CNPq.

${ }^{3}$ Doutor em Educação ICED/UFPA. Professor de filosofia da Educação da UFPA
} 


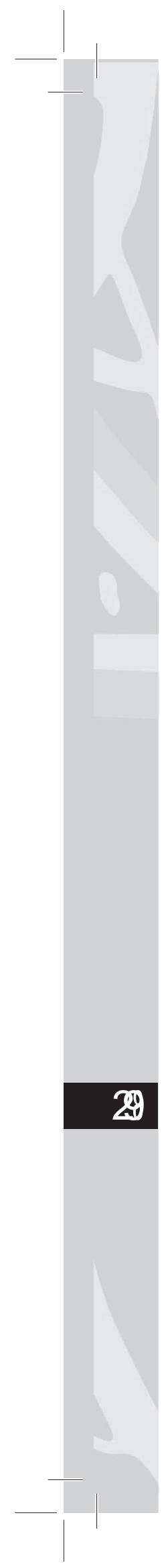

\begin{abstract}
The play activity in education, represented by plays and games, can develop a child's learning in the classroom. The playful poses as a teaching tool for performance and full development of children, providing moments of joy, learning and commitment to learning. Article and results of undergraduate research activities developed by the Group of Studies and Research in Education, Childhood and Philosophy - GEPEIF / CNPq/UFPA coordinated by professors Waldir Ferreira de Abreu and Damião Bezerra Oliveira and the bond extension project: The playful as teaching resource in the education of children. Aims to discuss the importance of playfulness in the process of child development, especially in kindergarten and provide recreational activities developed with the school children and the rivers Quianduba and Ajuai in a workshop on playful.
\end{abstract}

Keywords: Playfulness. Developing. Child.

\title{
Introdução
}

$\mathrm{O}$ artigo discute a ludicidade como instrumento de grande relevância para o desenvolvimento infantil. Procura explicar por que as crianças brincam, entendendo o brincar não só como prazer, mas como uma necessidade. Mostra o papel que o brinquedo exerce sobre o desenvolvimento perceptivo, o comportamento e a relação entre as crianças, principalmente as da educação infantil.

Enfatiza a importância das brincadeiras durante o processo de desenvolvimento cognitivo da criança, destacando-as não só como uma atividade prazerosa, mas fundamentalmente necessária que proporcionará os conhecimentos culturais que viabilizarão a sua integração, a inclusão, a socialização, bem como, o amadurecimento e o conhecimento do seu próprio eu. Também ressalta a contribuição do brinquedo como mediador na busca pela apreensão da realidade pela criança. No final, apresenta um conjunto de brincadeiras que foram desenvolvidas com crianças nas escolas dos rios Quianduba e Ajuaí, em Abaetetuba, e que pode ser usado pelo professor como atividades socializadoras e de aprendizagem na sala de aula. 


\section{Porque as crianças brincam?}

Esta pergunta pode parecer fácil e a resposta muito óbvia: uma criança brinca porque gosta, porque sente prazer. Mas, esta afirmação não é a única e nem a mais completa, pois existem brincadeiras que pouco estimula as crianças e são encaradas como chatas e sem graça.

A afinidade que as crianças possuem em relação às atividades lúdicas é inegável e, segundo alguns teóricos, como Piaget (2002) e Vygotsky (1998), faz parte da natureza das crianças o lidarem com o mundo de forma lúdica. Desta maneira, não é difícil para nós entendermos tal afinidade, e, mais ainda, não é de se estranhar que as crianças utilizem os brinquedos para, a partir deles, começarem o processo de exploração do mundo, e mais especificamente do ambiente que as rodeia: o ambiente familiar, o ambiente educacional, o meio social etc... É por meio da sua vivência lúdica que a criança interage com os brinquedos, com os objetos em geral e com as pessoas com as quais se relaciona e convive; a partir desta interação ela adquire conhecimento do mundo, o que a torna susceptível à socialização. Ao levarmos em consideração o processo de interação, socialização e exploração do mundo, observamos que cada criança faz parte de um processo natural da vida, e que essa interação constitui uma necessidade humana dela.

Do ponto de vista psicológico, a brincadeira está presente na vida da criança desde o seu nascimento. Piaget (2001), diz que as atividades lúdicas facilitam o desenvolvimento físico e mental da criança, já que o brincar exerce uma ação sobre ela, e ela, por sua vez, exerce uma ação sobre o brinquedo, dando a ele significados.

Sabemos que a brincadeira é uma atividade que as crianças gostam e que é necessária para sua vida, pois, assim como o ato de comer ou dormir, a brincadeira exerce uma função orgânica no desenvolvimento da criança. Também, é por meio da brincadeira que a criança constrói conhecimento sobre o mundo e sobre si mesma. Ao brincar, a criança interage com as pessoas, compartilhando seus valores culturais, éticos e morais. 


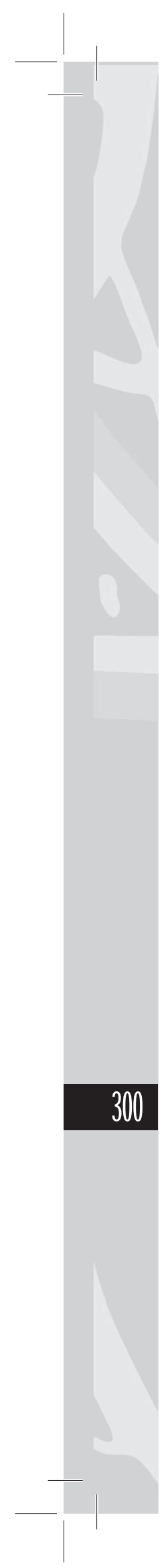

Com as atividades lúdicas, a criança passa a compreender as regras e os comportamentos e experimenta os mais diversos sentimentos: dor, tristeza, alegria, perda, desejo, prazer. Para a criança, a brincadeira é uma atividade completa, pois favorece as descobertas e os desafios necessários para o seu desenvolvimento.

\section{Nem sempre o brinquedo dá prazer à criança}

Segundo Vygotsky (2001), não podemos dizer que o brinquedo e a brincadeira são o que dão mais prazer à criança. Outras atividades são mais prazerosas do que o brincar, principalmente quando estamos nos referindo às crianças que se encontram na fase das funções psicológicas elementares. Nesta fase, é mais prazeroso para uma criança estar com a mãe ou colocar uma chupeta na boca. Algumas atividades do brincar envolvem situações em que a criança não se encontra satisfeita, portanto não sente prazer. Um exemplo são os jogos em que ela perde, já que busca sempre resultados positivos.

$\mathrm{Na}$ educação, a contribuição do brinquedo para o desenvolvimento da criança vem a ser uma espécie de recurso por meio do qual se obtém resultados importantes em relação à experiência que a criança passa a adquirir no seu cotidiano, que pode ser positiva ou negativa.

Dessa forma, o brinquedo vem como necessidade de educar e trabalhar o seu desenvolvimento intelectual de maneira mais prazerosa. Para o brinquedo ser considerado uma atividade educativa, temos que compreender primeiramente as necessidades das crianças, e, a partir destas, trabalhar o lúdico.

Para Vygotsky (1991), só o brinquedo, como imaginação em ação, é na verdade a primeira possibilidade de ação da criança numa esfera cognitiva capaz de contribuir para que ela ultrapasse essa dimensão perceptiva motora do comportamento. "É no brinquedo que a criança aprende a agir numa esfera cognitiva ao invés de uma esfera visual externa, dependendo das motivações e tendências 
internas e não dos incentivos fornecidos pelos objetos externos" (VYGOTSKY, 1991, p. 100-101).

Vemos, então, que no brinquedo os objetos perdem sua força determinadora e, ao brincar, a criança age independentemente do que vê, ela percebe o objeto não de maneira como ele é, mas como ela desejaria que ele fosse lhe conferindo um novo significado.

Segundo Piaget (2001), ao brincar, a criança apreende o mundo à maneira dela e sem compromisso com a realidade, pois a interação dela com o objeto não depende da natureza deste, mas da função que ela atribui a ele. Isto é o que ele chama de jogo simbólico, em que a criança representa um objeto por outro, atribuindo-lhe novos significados: como tornar um pedaço de madeira em boneco e um cabo de vassoura em cavalo (VYGOTSKY, 1991). Porém, isso não acontece com uma criança muito pequena, pois para ela é impossível separar o significado do que é visto - o significante.

É só na idade pré-escolar que ocorre pela primeira vez essa separação entre significado e significante, a partir daí a criança separa, no seu brincar, o pensamento do objeto, e sua ação vai surgindo das ideias e não das coisas. Entretanto, a criança não realiza essa separação de uma só vez, porque é extremamente difícil para ela, é somente com auxílio do brinquedo que ela vai conseguindo concretizar essa separação.

O que foi dito sobre a separação do significado dos objetos aplica-se igualmente às ações da criança. Por exemplo, quando uma criança bate com os pés no chão e imagina-se cavalgando um cavalo, ela está dando mais importância ao significado que está conferindo à ação do que à própria ação" (KISHIMOTO, 2001, p. 62).

Vemos então que no brinquedo, a criança separa significado de significante sem saber o que estar fazendo, atingindo assim uma definição funcional dos conceitos ou de objetos, e as palavras passam a se tornar parte de algo concreto. Dessa maneira, as maiores 


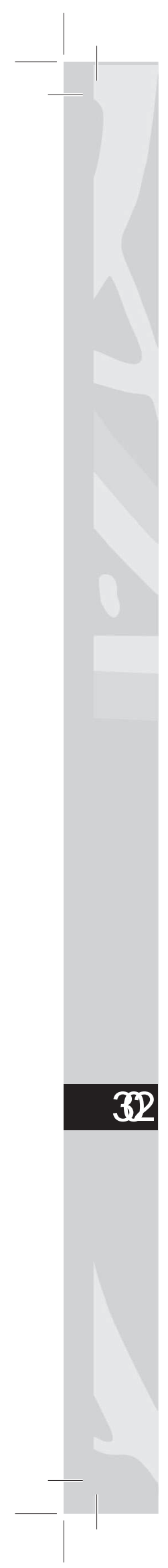

aquisições de uma criança são conseguidas por meio do brinquedo, e essas aquisições tonar-se-ão no futuro seu nível básico de ação real.

Portanto, vemos que a imaginação criadora da criança surge com o brinquedo que serve como o primeiro instrumento de enfrentamento da realidade, ampliando as possibilidades de ação e compreensão do mundo. O conhecimento que ela começa a adquirir deixa de estar preso ao aqui e agora, e o mundo inteiro passa a estar presente dentro do pensamento, já que é possível a ela imaginá-lo e representá-lo por meio de gestos, sons e palavras. No entanto, é importante ressaltar que o imaginário não se confunde com o real, ele apenas é um instrumento utilizado pela criança para compreender o real e se conscientizar dele. Essa capacidade que o brinquedo proporciona à criança de simbolizar e de brincar com a realidade por meio da fantasia e de símbolos é que permite a ela viver em uma nova dimensão da realidade: a dimensão simbólica, que a possibilita a interiorização do mundo.

\section{O brinquedo e sua influência na forma de comportamento humano}

O papel que o brinquedo exerce na forma do desenvolvimento das crianças é indispensavelmente importante, visto que elas vivem no mundo de faz de conta no qual a criatividade e a imaginação de situações são características. De acordo com Froebel, não existe nenhum mecanismo tão importante como o brinquedo no desenvolvimento da infância, já que, nas palavras dele:

A brincadeira é a atividade espiritual mais pura do homem neste estágio e, ao mesmo tempo, típica da vida humana enquanto um todo... Ela dá alegria, liberdade, contentamento, descanso externo e interno, paz com o mundo... O brincar em qualquer tempo não é trivial, é altamente sério e de profunda significação. (FROEBEL, 1912, apud KISHIMOTO, 2001, p. 55). 
O brincar aparece como uma situação em que a criança se encontra livre para agir da forma que deseja. É assim, quando brinca de casinha, de professora, de mãe e filha, de super-heróis... Ela se comporta segundo os padrões do adulto, ou melhor, tenta se comportar de forma a superar os obstáculos da vida real, como: se vestir, comer sem deixar cair, tomar banho sozinha, lavar as mãos, escovar os dentes etc. Uma das formas de exemplificar isso é quando brincando de boneca a criança repete o que muitas vezes sua mãe diz a ela.

É na brincadeira, que criando uma situação imaginária, a criança assume um papel e, a partir daí, cria um comportamento segundo observa no seu cotidiano. Assim encontramos mais um fator além da imaginação no ato de brincar, que é a imitação, pois, quando se brinca, essas duas características estão interligadas, sem deixar de mencionar algumas regras do comportamento, que vêm do próprio relacionamento humano.

É importante que se destaque que, implícita ou explicitamente, é a partir do brincar com situações de fatos cotidianos que a criança começa involuntariamente a perceber como os grupos sociais se comportam, e, assim, aprende, nos relacionamentos humanos, que tipo de atitude tomar tanto na infância como na adolescência, na juventude ou na idade adulta; pois, no brinquedo, ela se comporta além do comportamento de sua idade.

\begin{abstract}
A existência permanente de uma alternância entre distanciamento e adesão da realidade é o que permite à criança que brinca dois tipos de movimentos opostos: a libertação e a imersão do real. Tanto um quanto outro movimento se modificam à medida que a criança vai desenvolvendo sua capacidade de brincar dentro das condições histórico-culturais de que dispõe (LIBRANDI DA ROCHA, 1994, p. 63).
\end{abstract}

Entender o importante papel que o brinquedo exerce no presente e no futuro da criança deve ser fundamental para pais e educadores, a fim de que incentivem essa prática na infância. $O$ 


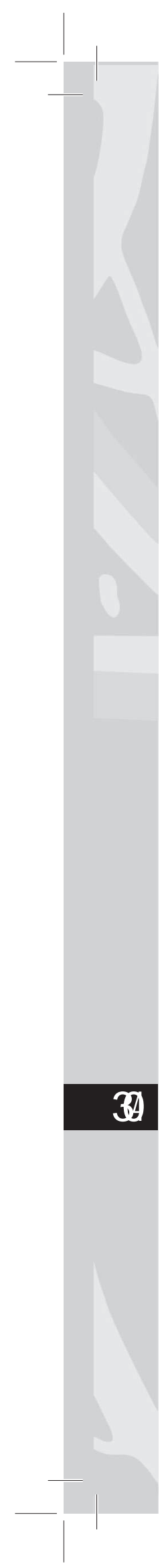

educador deve envolver, necessariamente, a criança em brincadeiras, sejam elas as mais variadas, como um processo de inclusão e de socialização para o seu desenvolvimento integral.

\section{Brincando e aprendendo a brincar}

As oficinas realizadas nas ilhas aconteceram dentro de sala de aula com os alunos da educação infantil e do ensino fundamental. As turmas foram divididas por série e planejadas da seguinte maneira:

$\mathrm{Na}$ ilha de Quianduba, as crianças foram organizadas em duas turmas: a turma da educação infantil ficou em uma sala e a turma do ensino fundamental ficou em outra sala. Os bolsistas da Universidade Federal do Pará, do Campus de Abaetetuba, que fazem parte do projeto, se dividiram em dois grupos de três bolsistas, e cada grupo ficou responsável por uma turma em que foi realizada a oficina.

$\mathrm{Na}$ ilha de Ajuaí, as crianças foram divididas em três turmas de alunos, por série e idades, e em cada turma três bolsistas ficaram responsáveis para socializar e contribuir com os conhecimentos adquiridos no decorrer de seus estudos, mostrando para as crianças como seriam realizadas as atividades. Aproveitamos e passamos para as crianças a importância do brincar e interagir com os demais.

Apresentamos aqui um conjunto de brincadeiras que desenvolvemos com as crianças que participaram da oficina sobre o lúdico, realizada nas Escolas dos rios Quianduba e Ajuaí - município de Abaetetuba.

\section{ESQUILO SAI DA TOCA}

Faixa etária: crianças até 08 anos.

Objetivo: mostrar a criança a importância do trabalho em grupo, da organização, da concentração e da atenção.

Material: um apito ou sino.

Metodologia: os jogadores são numerados e agrupados de $3 \mathrm{em}$ 3. De cada três, dois formarão a toca (mãos dadas e levantas), e o terceiro será o esquilo. As tocas formarão um círculo com bastante 
distância entre uma e outra. No centro haverá um ou dois esquilos sem toca. A cada 5 minutos haverá troca de papéis: um da toca será esquilo e o esquilo será a toca.

Ao sinal de iniciar, os esquilos procurarão trocar de tocas, e então o esquilo do centro se apropriará de uma das tocas. $O$ esquilo que ficou sem toca irá, por sua vez, para o centro. O jogo prossegue assim até que todos os jogadores tenham oportunidade de serem esquilos.

\section{OS PEIXES}

Faixa etária: crianças até 08 anos.

Objetivo: desenvolver a concentração e a atenção, além dos conhecimentos sobre animais aquáticos (marinhos).

Material: giz ou caneta piloto.

Metodologia: os jogadores, aos pares, ocupam os círculos de mais ou menos $50 \mathrm{~cm}$ de raio feito no chão e escolhem em segredo nomes de peixes. Dois jogadores ficam fora dos círculos: são as baleias.

As baleias de mãos dadas passeiam pelo campo e dizem nomes de peixes. Os pares, cujo nome foi citado saem do círculo e acompanham o passeio das baleias. Em dado momento, as baleias dizem: - O mar está calmo. Os peixes que ainda estão nos círculos saem imediatamente a passeio. Quando as baleias falarem: - O mar está agitado! - todos correm, procurando se colocar num dos círculos, inclusive as baleias. O par que ficar sem círculo será agora as baleias. Os outros escolhem novos nomes e tudo recomeça.

\section{ATRAVESSAR O REGATO}

Faixa etária: crianças até 08 anos.

Objetivo: prática esportiva que pode melhorar o equilíbrio.

Material: giz ou caneta piloto.

Metodologia: os jogadores formam uma coluna e, à distância de 3 a 5 metros, traçam-se duas linhas paralelas proporcionais ao tamanho dos jogadores.

Cada jogador pula por cima do "riacho". Quem não consegue atingir a outra margem cai n'água e fica molhado. Precisa ir sentar-se 


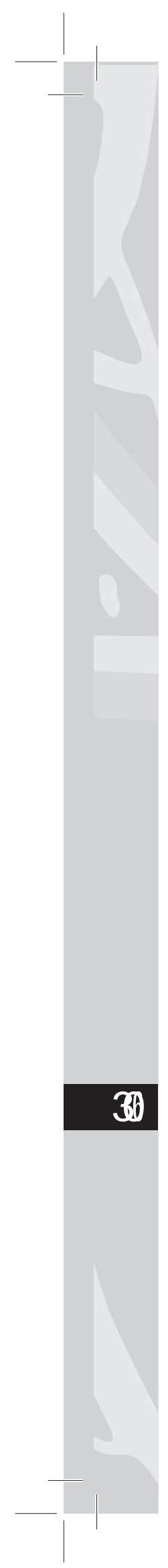

ao sol para secar a roupa. Quando todos tiverem pulado, aumenta-se a largura do riacho e os que conseguiram atravessá-lo da primeira vez, tentarão novamente. O jogo prossegue assim, até que todos os jogadores tenham caído na água. Será vencedor, o último que ficar seco.

\section{O RABO DO BURRO}

Faixa etária: crianças até 08 anos.

Objetivo: desenvolver a noção de espaço e coordenação motora sem o uso da visão.

Material: giz (ou caneta piloto) e um lenço para vendar os olhos.

Metodologia: formação livre.

Desenha-se no chão ou no quadro-negro um burro de tamanho razoável sem, porém, colocar-lhe o rabo. Em seguida, o primeiro candidato é levado até perto de onde está desenhado o burro. Seus olhos são vendados e dá-se uma ou duas voltas para que ele perca a noção de lugar. Em seguida ele terá de desenhar o rabo do burro.

Caso seja no quadro-negro, não poderá se orientar pelas bordas do quadro. A plateia não poderá auxiliar. Em seguida, outro concorrente tentará. Será vencedor o concorrente que mais se aproximou do lugar certo do rabo do burro.

\section{CENTOPEIA EM ACÃO}

Faixa etária: crianças até 08 anos.

Objetivo: trabalhar o equilíbrio, a união do grupo e uma boa coordenação motora.

Material: giz ou caneta piloto.

Metodologia: dividem-se os jogadores em dois grupos com igual número de participantes. Marca-se uma linha de saída e, a 10 metros desta, a linha de chegada. Os jogadores formam colunas segurando um na cintura do outro e todos de cócoras. O primeiro jogador cabeça de centopeia - segurará as mãos do que está atrás de si.

Dado o sinal, a centopeia sairá de sua linha e deverá dirigir-se à linha de chegada avançando aos pulos, sem se erguer. É necessária 
uma boa coordenação motora para que todos pulem juntos e assim avancem mais rapidamente. Cada jogador que transpuser a linha de chegada desliga-se da centopeia. Será vencedor o partido cujo último jogador transpuser por primeiro a linha de chegada.

\section{A REDE}

Faixa etária: crianças até 08 anos

Objetivo: trabalhar a união do grupo, coordenação motora e o reflexo rápido.

Material: giz ou caneta piloto.

Metodologia: duas colunas de jogadores, rede e peixes se defrontam atrás de linhas paralelas, a uma distância de 10 metros. Na linha da rede, os jogadores dão-se as mãos, sendo em menor número. $\mathrm{Na}$ coluna dos peixes, os jogadores estão livres.

Dado o sinal de iniciar, as duas colunas avançam para o centro, e quando a rede perceber que há possibilidade, os dois jogadores extremos dão-se as mãos, formando a rede. Os peixes que neste momento estiverem no interior da rede tornam-se prisioneiros e vão para o aquário, no campo inimigo.

Os peixes não podem escapar pelas extremidades da rede, mas sim passar por entre as "malhas" (entre os braços dos jogadores que formam a rede).

No momento em que o círculo se fecha, nenhum jogador pode mais escapar. Será vencedor o peixe que por último for capturado.

\section{SACOS AMBULANTES}

Faixa etária: crianças até 08 anos.

Objetivo: trabalhar o equilíbrio, noção de competitividade honesta e atenção.

Material: um saco e uma corda para cada jogador.

Metodologia: traçam-se duas linhas paralelas, a uma distância de 10 metros. Atrás da linha de partida ficam os jogadores. Todos devem entrar no saco e amarrá-lo na cintura. 
Dado o sinal, partem todos os jogadores em direção à linha de chegada, podendo somente caminhar, nunca pular. Se algum jogador pular, voltará à linha de partida, reiniciando a caminhada.

Será vencedor o jogador que por primeiro atingir a linha de chegada. Se houver empate, haverá nova disputa entre os concorrentes, até que o vencedor seja um só.

\section{CARNEIRINHOS FUIÕES}

Faixa etária: crianças até 08 anos.

Objetivo: trabalhar o equilíbrio, a atenção, a coordenação motora, os reflexos de percurso normal e de costas, sem visão.

Material: garrafas plásticas ou hastes de madeira e um apito.

Metodologia: as crianças (carneirinhos) ficam tranquilamente dentro do aprisco, de gatinhas. As garrafas devem ser colocadas a uma distância que permita a passagem das crianças entre uma e outra. Fora ficará o pastor.

A um sinal do juiz, os carneirinhos resolvem fugir do aprisco. Saem, então, de gatinhas e passam por entre as garrafas. Quando o pastor vê suas ovelhas fugindo, trila o apito e então os carneirinhos devem voltar para o aprisco, sempre de gatinhas, desta vez, porém, de costas e sem poder olhar para trás. A ovelhinha que derrubar uma garrafa voltará para o aprisco e não poderá tentar nova fuga. Os demais tentam nova fuga, e assim prossegue até que reste um ou dois carneirinhos que serão considerados vitoriosos.

\section{O GUARDA}

Faixa etária: crianças até 08 anos.

Objetivo: desenvolver na criança a coordenação motora, a capacidade de defesa, as estratégias de direção e mira.

Material: uma garrafa plástica e uma bola.

Metodologia: os jogadores formam um círculo mantendo uma distância de meio metro entre um e outro. No centro fica a garrafa e um jogador (o guarda). 
Um jogador que estiver com a bola tenta derrubar a garrafa. O guarda deve defendê-la. Pode fazê-lo, utilizando-se de todos os meios, menos tirar a bola das mãos de um jogador. Estes, por sua vez, não podem se movimentar dos seus lugares, mas podem fazer passes com a bola, escolhendo ângulos mais fáceis e vulneráveis, em que o guarda não esteja tão atento. No momento em que um jogador conseguir derrubar a garrafa com a bola, o guarda será substituído por ele, e o jogo prossegue.

\section{PINGUIM MALUCO}

Faixa etária: crianças a partir de 3 anos.

Objetivo: coordenação, noção espacial, atenção, concentração.

Material: não há necessidade.

Metodologia: todas as crianças começam a imitar um pinguim e ao sinal do educador param. Uma criança é apontada e deverá fazer um movimento para que todos a imitem. Logo a seguir todos voltam a imitar o pinguim.

Nesta atividade todos participam ativamente e pode-se mudar, imitar outros bichos.

\section{ELEFANTE/ GIRAFA}

Faixa etária: crianças até 3 anos.

Objetivo: desenvolver os reflexos, a coordenação motora, a agilidade flexibilidade e audição.

Material: não há necessidade.

Metodologia: os brincantes devem estar organizados em forma de círculo. $\mathrm{O}$ animador deverá ir para o centro do círculo para dar o comando: "elefante" ou "girafa". Se o comando for "elefante", os brincantes deverão executar o gesto de elefante; se for "girafa", os brincantes farão o gesto de girafa.

Quando o animador disser "elefante", todos os brincantes devem ficar com as mãos na altura dos ombros esticadas para frente. Quando o animador disser a palavra girafa, os brincantes devem colocar as mãos para o alto esticando os braços. $\mathrm{O}$ brincante que 


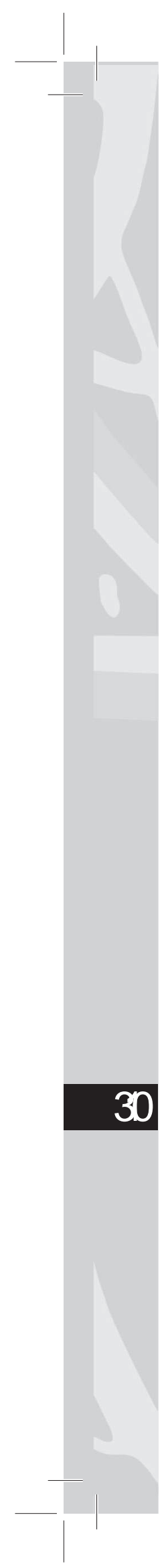

errar o comando irá para o centro animar a brincadeira e quem estava animando assumirá seu lugar.

\section{IDENTIFICACÃO}

Faixa etária: crianças de 1 a 3 anos.

Objetivo: desenvolvimento do pensamento simbólico, reconhecimento de imagens, enriquecimento de imagens, enriquecimento do vocabulário e identificação.

Material: livros e revistas ilustradas com gravuras atraentes e com perfeita nitidez.

Metodologia: por meio de diálogo com a criança, procura-se levá-la a reconhecer e a identificar os nomes das coisas. O adulto, por exemplo, mostra à criança gravuras de diferentes objetos, e pronuncia seus nomes, um a um, lenta e claramente. Pode também pedir à criança que distinga cada um dos objetos, perguntando-lhe: onde está o carro? A bola? O triciclo? Etc.

\section{Considerações Finais}

Os jogos e as brincadeiras são agradáveis, motivadores e enriquecedores. São elementos que podem fazer parte de nossas atividades pedagógicas, por possibilitarem o aprendizado de várias habilidades e também auxiliam no desenvolvimento sociocultural das crianças.

Podemos dizer que, por meio das atividades lúdicas, vivenciamos diversão, prazer, mas é principalmente aprendizado. A vivência de atividades lúdicas permite a valorização da cultura e da identidade dos que delas participam, sem desconsiderar os fatos, mas é atribuída às situações reais. Consequentemente, estas situações estimulam momentos de criatividades individuais e coletivas; crescimento intelectual e moral.

Finalizando, podemos pensar em como os brinquedos e as brincadeiras são coisas que deveriam ser levadas "a sério" no ambiente 
educacional. Cada um de nós possui um conhecimento amplo, além de muito rico, dos jogos da nossa infância. Socializá-los com a educação para as atuais gerações é uma tarefa muito importante: significa não somente o resgate da cultura lúdica, a sua preservação e continuidade, como também mostra a valorização da prática do lúdico no seu aspecto educacional.

As experiências com as crianças foram muito importantes, pois elas aceitaram bem os brinquedos e as brincadeiras realizadas durante os dois dias que passamos em cada ilha, se divertiram com os brinquedos confeccionados por elas, muitos deles feitos com materiais reciclados. Ficaram entusiasmadas com a nossa presença, pois representamos a novidade e a alegria. Para as crianças, fizemos a diferença, foi possível notar por meio das emoções e da sensibilidade que cada criança sentiu ao construir seu próprio brinquedo em sala de aula, já que saíram da mesmice. De forma entusiasmada, sempre perguntavam se nós iríamos voltar novamente para fazermos brinquedos com elas.

Acreditamos que a oficina que realizamos foi importante na medida em que pode contribuir para nossa formação como alunos de pedagogia e para o nosso aprofundamento no entendimento da atividade do brincar e do próprio brinquedo como um instrumento de socialização, desenvolvimento e ligação entre o imaginário e o real na criança. Esperamos que esse artigo possa despertar nos pais e nos professores o interesse em voltar a ser criança, e que voltem a brincar com seus filhos e com seus alunos. Para nós, como alunos de iniciação científica, essa atividade foi relevante e significativa, uma vez que experimentamos, na prática, o fazer pedagógico.

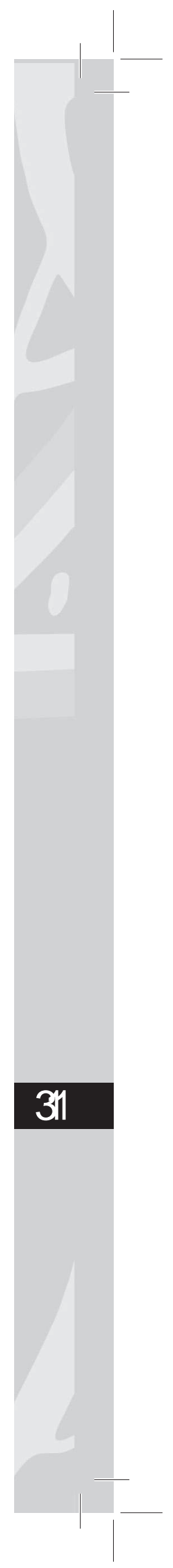




\section{REFERÊNCIAS}

ABREU, Waldir Ferreira de; OLIVEIRA, Damião Bezerra; MEDEIRAS, Wanderleia Leitão. Brincadeiras e brinquedos cantados: elementos imprescindíveis na educação de crianças. $2^{\mathrm{a}}$ ed. Belém: GEPEIF, 2013.

KISHIMOTO, Tizuko Morchuda. Jogo, Brinquedo, Brincadeira e Educação. $5^{\text {a }}$ ed. São Paulo: Cortez, 2001.

LIBRANDI DA ROCHA. Podemos brincar. In: BROUGERE, GAILES. Brinquedo e Cultura. São Paulo: Cortez, 1997.

REIDMANN, Adriana et al. O direito de Brincar: a brinquedoteca. São Paulo: Scritta ABRINQ, 1992.

SANTOS, Santa Marli Pires; CRUZ, Dulce Regina Mesquita da. Brinquedo e Infância: um Guia Para Pais e Educadores em Creche. Rio de Janeiro: Petrópolis, 2000.

VYGOTSKY, L. S. A Formação Social da Mente: o Desenvolvimento dos Processos Psicológicos Superiores. São Paulo: Martins Fontes, 1991. 